\title{
Goals and Design of the Project and Basic Information About Sharon's Case
}

\author{
MICHAEL A. WESTERMAN, ${ }^{a, c, d}$ \& KENNETH L. CRITCHFIELD ${ }^{b, d}$
}

\author{
${ }^{\text {a }}$ New York University \\ b James Madison University \\ ${ }^{\mathrm{c}}$ Correspondence regarding this article should be sent to: Michael A. Westerman, Department of Psychology, New \\ York University, 6 Washington Place, Fourth Floor, New York, NY 10003, USA. \\ Email: michael.westerman@nyu.edu \\ $\mathrm{d}$ The authors are grateful to the Brief Psychotherapy Research Project (J. Christopher Muran, Principal \\ Investigator) at Mount Sinai Beth Israel Medical Center, New York, for making available material on the case \\ reported on in this set of articles.
}

\begin{abstract}
This paper sets the stage for subsequent papers in this set of articles, which collectively offer a comparative examination of two approaches to case formulation and treatment by examining the same case from the two theoretical perspectives. One approach is based on Interpersonal Defense Theory (e.g., Westerman, 2018, 2019), the other is Interpersonal Reconstructive Therapy (IRT, Benjamin, 2006, 2018). In this paper, we present the goals of the project and its design, which was novel in some respects. We also introduce the case by presenting basic clinical information about the patient, Sharon (pseudonym), and describing the short-term therapy approach that was employed. The concluding section introduces the subsequent papers in this set, which includes a commentary by Stanley Messer that raises fundamental methodological/philosophy of science issues about comparing the relative merits of different therapy approaches and a reply to that commentary that addresses the important questions it poses.
\end{abstract}

Keywords: Interpersonal Defense Theory; Interpersonal Reconstructive Therapy (IRT); case formulation; comparing therapy approaches; philosophy of science; case study; clinical case study

This issue of PCSP presents a comparative examination of two approaches to case formulation and their implications for treatment in the specific case of "Sharon." One approach is based on Interpersonal Defense Theory (e.g., Westerman, 2018, 2019), the other is Interpersonal Reconstructive Therapy (IRT; Benjamin, 2006, 2018). Focusing on the same case makes it possible to compare these two perspectives in a detailed, concrete manner and clarify commonalities and differences in what they lead to when it comes to actual clinical work.

There have been a few previous contributions that also have used a case study to concretely compare different therapy approaches (e.g., Messer, 1986; Lazarus \& Messer, 1988), but this way of employing case studies has been largely neglected, even though it has much to offer. We should also note that, as we explain shortly, the present project is unique in certain respects as compared to prior efforts that were broadly similar. 


\section{GOALS}

We had several goals for this project. For one thing, we thought that carefully examining the implications of the two perspectives for the same case would prove helpful for clinical training and research concerning each of the approaches, because comparing the two in the present project would sharpen appreciation of their respective key features. For similar reasons, we also thought that this project would provide useful insights for possible future complementary process-outcome nomothetic research comparing the effectiveness of the two approaches.

Other goals for the project were based on the fact that the two perspectives appear at first viewing as similar in the broad sense that they are both interpersonal approaches. On one hand, this led us to speculate that the project might point to possibilities for integration. In the most ambitious sense, that might involve theoretical integration, that is, recognizing that the perspectives could be incorporated in a single overarching theory. In a more limited sense, possibilities of integration might involve recognizing ways that specific types of interventions suggested by one approach could be assimilated by the other. Looking at things in a very different way, there was also the possibility that the results of the project might suggest that there are fundamental differences between the two approaches even though they are both interpersonal. Findings of this sort would provide a cautionary comment about current efforts aimed at psychotherapy convergence (e.g., Henriques, 2017).

In what follows in this paper, we first describe the design of the project and discuss its novel features. We also provide information about the large nomothetic study that included Sharon's case and explain how that case was selected for the present case study project. In addition, we describe the extensive data set that was the basis for the analyses we conducted of Sharon's case from the two theoretical perspectives.

We also offer remarks about basic methodological issues regarding the relationship between theory and data. These issues are relevant for all case study research and, beyond that, research on psychotherapy quite generally, but they are highlighted by the procedures we employed.

We then introduce the reader to Sharon's case by providing some basic clinical data about the case, including information about the problem that was the main focus of the therapy. We also describe the therapeutic approach that was taken in the case, a manualized, short-term dynamic therapy called Brief Adaptive Therapy (BAP; Pollack, Flegenheimer, Kaufman, \& Sadow, 1992). Importantly, BAP is different from both Interpersonal Reconstructive Therapy and Interpersonal-Defense-Theory-based therapy (more on this point below). Finally, we introduce the other papers in this set of articles by briefly indicating what each one addresses.

\section{DESIGN}

The design of this project was novel in two respects. First, because the case was drawn from a large nomothetic study, an extensive set of quantitative and qualitative data was available. As a result, both the first author (MW), who examined the case from the perspective of Interpersonal Defense Theory, and the second author (KC), who analyzed it from the viewpoint 
of IRT, had access to the original source information we each needed to arrive at independent case formulations from our respective viewpoints. Neither of us was in the situation of trying to think about the case from our own point of view based only on a limited clinical report that was generated from another viewpoint, as is often the case when theoretical approaches are compared. In a situation of that sort, it is very difficult if not impossible to arrive at a case formulation from the "other" vantage point with any confidence. And without a case formulation, it is difficult to recommend alternative interventions based on the "other perspective" that might have been more effective.

The other novel feature of the design concerns the BAP therapeutic approach that was employed in Sharon's case. This model was different from both IRT and Interpersonal Defense theory. However, it was similar enough to these perspectives so that the psychotherapy session material added important information to the large amount of other data that was available about the case that was useful to both MW's and KC's efforts to arrive at a formulation of the case. Hence, the design was quite different from the situation in which a therapy case was conducted based on one of two perspectives that investigators are trying to compare.

\section{Umbrella Investigation and Case Selection}

Sharon's case was part of a large nomothetic study conducted by Muran, Safran, Samstag, and Winston (2005). That study, which we will refer to as the "umbrella" investigation, investigated three brief (30-session) therapy approaches to the treatment of patients with diagnoses of a Cluster C personality disorder (PD) or PD not otherwise specified. Muran et al. (2005) found that patients in all three treatment conditions showed significant improvement. The case we examined was selected from the BAP short-term dynamic therapy condition of the umbrella study mentioned above. As noted above, the umbrella investigation offered an excellent context for the present case study project because (a) a wide range of quantitative and qualitative data was collected about all cases, including Sharon's, and (b) the BAP treatment condition was different from both of our approaches, which was an advantageous feature of the design for comparing our approaches, yet similar enough to provide useful information for case formulations based on both of our theoretical perspectives.

One of the criteria for selecting the case for this project was a nearly complete data set. The primary criterion for selecting the case was poor outcome because that would provide an opportunity to examine processes that contribute to unsuccessful treatment.

Outcome was assessed on six measures, including patient and therapist ratings of Target Complaints (TC; Battle et al., 1966); therapist assessments on the Global Assessment Scale (GAS; Endicott, Spitzer, Fleiss, \& Cohen, 1976); and patient reports on the Symptom Checklist90-Revised (SCL-90R; Derogatis, 1983), the Inventory of Interpersonal Problems-64 (IIP; Horowitz, Alden, Wiggins, \& Pincus, 2000), and the Wisconsin Personality Disorder Inventory (WISPI; Klein, Benjamin, Treece, Rosenfeld, \& Greist, 1993).

Sharon's case met specific pre-established criteria for selection as a poor outcome case because there was clinically significant improvement on only one of six outcome measures. In 
addition, the data set for the case was nearly complete. A previous paper on the case includes additional information on the selection procedure (Westerman \& Muran, 2017).

As we noted earlier, the umbrella investigation offered an excellent context for our project because a wide range of quantitative and qualitative data had been collected about all of the cases, including Sharon's, in addition to the outcome measures. The data set included questionnaires that had been developed especially for the umbrella study, which inquired about a broad range of psychological problems, family relationships, and other matters; a number of previously developed self-report instruments that Sharon completed, many of which focused on interpersonal relationships; post-session questionnaires that had been completed after every session, that included several measures such as the Working Alliance Interview (Tracey \& Kokotovic, 1989) as well therapist progress notes about each session. Also, diagnoses had been determined in the umbrella study using parts 1 and 2 of the Structured Interview for DSM-III-R, I \& II (Spitzer, Williams, Gibbon, \& First, 1990).

In addition, for a number of sessions that occurred at different points over the course of the therapy, MW had access to video-recordings of the sessions and $\mathrm{KC}$ had access to lengthy session summaries and some transcript material that had been prepared previously as part of the umbrella investigation. The session summaries were lengthy and although they were not transcripts that recorded every turn, they described what happened chronologically and concretely, noting, for example, that the therapist began the session by asking Sharon how she felt about an event that had occurred, then indicating how Sharon replied, and so forth. The difference here between the materials available to MW and $\mathrm{KC}$ resulted from logistical and Institutional Review Board considerations. It did not create any difficulties because both of us had access to the kind of information that we needed about the sessions for formulation purposes, given our theoretical perspectives (see below). Finally, both of us had access to logs that noted very briefly and in very simple terms the main topic or topics discussed in every five-minute segment of all 30 sessions in Sharon's therapy.

\section{Relationship Between Theory and Data}

Not surprisingly, neither MW or KC refer to all of the material in the above-described voluminous data set in the subsequent papers in this set of articles that provide views of Sharon's case from the vantage points of IRT and Interpersonal Defense Theory. Moreover, our papers based on each of those theoretical perspectives do not refer to the same subset of data. Thus, although we both had access to and became familiar with virtually identical sets of information about Sharon, our different theories led us to focus on different data in our analyses and interpretations of Sharon's case. Specifically, we arrived at very different formulations of Sharon's case as a result of our different theoretical perspectives, including the implications of those perspectives for the ways in which we selected from and considered the clinical data.

These differences in the information we each focused on will be evident in the subsequent papers in this set. We comment on those differences at some points in those papers, but at this juncture we can note the main difference in focus. Although both IRT and Interpersonal Defense Theory call for attending to in-session narratives and questionnaire responses about early family history and current relationships, on the one hand, and process in 
the therapy relationship, on the other hand, due to the nature of its theoretical perspective IRT gives the former relatively more weight when making a case formulation, whereas Interpersonal Defense Theory gives the latter relatively more weight.

The design of this project highlights the role played by theory in how clinical data is selected and treated in developing case formulations because the project was based on a large data set and that data set was not limited to information previously identified as relevant from only one of the two perspectives. Note, however, that arriving at a formulation of a case and its associated implications for treatment is quite generally regarded as a theory-driven process in which differences in theoretical perspectives lead different clinicians or researchers taking a case formulation approach to focus on different kinds of clinical data as they develop an understanding of a case (Eells, 2007; Kramer, 2019; Person, 1991).

Also note that the theory-driven nature of the case formulation process does not mean that a clinician or researcher focuses only on clinical data that support a provisional formulation. Rather, the theory provides guidance about what clinical evidence is relevant, and that certainly can include evidence that calls for revising a formulation or abandoning it altogether in favor of a very different formulation based on the guiding theory. If IRT and Interpersonal Defense theory focus on different kinds of clinical data, the questions arise: (1) Are these two theories incommensurate such that it is not viable to compare the validities of case formulations based on them? and (2) Are these two theories incommensurate such that it is not viable to empirically compare their relative effectiveness? We believe the answer to both questions is no, they are not incommensurate. To explain our position we will return to these issues and discuss them at some length in the final paper in this set of articles.

\section{Structural Analysis of Social Behavior (SASB)}

Both MW and KC employed the Structural Analysis of Social Behavior (SASB; Benjamin, 1979) to provide ways of conceptualizing parts of the clinical data. SASB is a sophisticated, descriptive model of interpersonal behavior. We offer an initial description of the model here. Subsequent papers describe the system in detail and how it was employed by MW and $\mathrm{KC}$.

As shown in Figures 1 and 2, which are two versions of the model, SASB is based on three dimensions, affiliation, interdependence, and focus. The three circumplexes in Figure 1 are differentiated by the focus dimension, that is, the attentional focus of a behavior. The "Other" focus refers to transitive behaviors, that is, behaviors that are to, for, or about another. The "Self" focus refers to intransitive behaviors, or behaviors that are to, for, or about self in relation to another. Whereas these first two foci are considered "interpersonal," a third focus is described as "intrapsychic," and it is labeled "Introject." The Introject focus refers to how a person treats himor herself.

Two orthogonal dimensions differentiate the space within each focus. An affiliation axis runs from extremes of friendliness to hostility. An interdependence axis runs from extremes of independence/differentiation to interdependence/enmeshment. 
We can help clarify these brief remarks about the focus, affiliation, and interdependence dimensions by pointing out the extreme points of affiliation and interdependence on each of the three foci, as depicted in Figure 1. On the Other focus, affiliation runs from "tender sexuality" to "annihilating attack," and the interdependence axis runs from "endorse freedom" to "manage, control." On the Self focus, the affiliation axis varies from "ecstatic response" to "desperate protest," and interdependence varies from "freely come and go" to "yield, submit, give in." On the Introject focus, affiliation runs from "love, cherish self" to "torture, annihilate self," and the interdependence dimension varies from "happy-go-lucky" to "control, manage self." Within each focus, behaviors appear in a circular ordering based on respective combinations of affiliation, and interdependence.

SASB has been used as a largely descriptive measurement system (although this is not to say that the model is theory free). It also has been used in an explicitly theory-based manner, because there are theoretical principles linked to the SASB model about such things as how a person is likely to respond on the Self focus if he or she is interacting with someone who behaves in a particular way on the Other focus; and how a person is likely to relate to significant others as an adult if that individual's parents treated him or her in a certain manner when the person was a child (Benjamin, 1979, 1987).

Another important point to note here is that several different versions of the basic model have been developed. These versions differ from each another in how finely the two-dimensional circumplex surfaces are divided up. For example, and as shown in Figure 1, in what is called the "full model," 36 points are identified around each circumplex. In the cluster model, which is shown in Figure 2, each focus is divided into 8 segments. (Note that the focus dimension is not represented the same way in Figure 1 and Figure 2. In Figure 1, Other, Self, and Introject are represented by three circumplexes. In Figure 2, the other, self, and introject foci are represented respectively from top to bottom by the three words that appear one under the other in each cluster, but the figure could be drawn as three circumplexes.)

Although both KC and MW made use of SASB in their analyses of Sharon's case, they employed it in different ways due to the theoretical perspectives that guided their efforts. MW used the full model to characterize interpersonal behaviors because Interpersonal Defense Theory calls for making very careful discriminations between behaviors, including those that are placed reasonably near each other on the circumplex. $\mathrm{KC}$, on the other hand, used the cluster model because it has been emphasized in Benjamin's $(2006,2018)$ articulation of IRT. Another difference related to how we employed SASB is that KC's formulation was based on many of the explicit theoretical principles linked to the SASB model because those principles are themselves part of the IRT theoretical perspective. By contrast, Interpersonal Defense Theory only makes use of one of the principles associated with SASB, the principle of complementarity, and so it is the only one of those principles that entered into MW's formulation of Sharon's case.

The basic SASB model will become much more clear in subsequent papers in this set of articles when MW and KC employ it in their analyses of Sharon's case. Those papers also clarify why we used different versions of the SASB model (i.e., Figure 1 or Figure 2); provide detailed information about the theoretical principles associated with SASB; and clearly show why there 
are differences in how IRT and Interpersonal Defense Theory made use of those principles, which will become possible once we present our two guiding perspectives.

\section{BASIC INFORMATION ABOUT SHARON'S CASE}

In this section, as an introduction to Sharon's case, we present clinical information that is descriptive and not interpreted through the lens of a particular theory. Such a description provides a common knowledge base about Sharon for clinicians from a wide range of theoretical orientations and helps to set a context for understanding the particular theory-guided analyses of MW and KC.

\section{Demographic Information, Diagnosis, and Presenting Problems}

At the time of this therapy, Sharon was a 28-year-old unmarried white female. She had not been married previously and had no children. She lived with her sister. Sharon was a social worker with an MSW degree who worked with disadvantaged children.

As noted earlier, diagnoses were determined in the umbrella study using the Structured Interview for DSM-III-R (Spitzer et al, 1990). Sharon's diagnosis at intake was Anxiety Disorder NOS on Axis I; and Avoidant PD, Self-defeating PD (which was a DSM personality diagnosis at the time of the umbrella project), and Paranoid PD on Axis II.

Sharon entered therapy saying that she wanted to get over her relationship with a man we will refer to as Jeff, but Sharon also said that she still loved Jeff. This issue was the central focus of most of her therapy sessions. The central importance of this issue for Sharon also was reflected in the fact that the first two of her Target Complaints were (1) "guilt and agony" about her broken engagement with Jeff, an engagement she had ended roughly one and a half years before beginning treatment, and (2) "difficulty moving on and leaving the past behind." At midphase of her therapy, Sharon added a third item to her list of target problems, which was "dealing with the attachments in my family."

Sharon's presenting problems also included anxiety coupled with diminished concentration, and procrastination about work and a planned writing project. In addition, interview notes indicate that she self-reported problems with anger and guilt. She also described herself as worrying about the health of significant others (including her ex-fiancé and father, among others) to the extent that she "obsess[ed]" about "death, illness, endings, people growing apart and moving on." For example, she said that she worried about her father traveling by plane, even though he was healthy.

\section{Sharon's Relationship with Jeff}

Sharon and Jeff had been in a relationship for $5 \frac{1}{2}$ years and then got engaged. Six months later, Sharon called off the wedding because Jeff refused when she wanted them to go to couples therapy to work on problems in their relationship before they got married. Specifically, Sharon had concerns about Jeff's temper. Sharon cancelled the wedding four months before the planned event. She described ending the relationship as "the cruelest thing I could do" to Jeff. As 
noted above, Sharon broke off the engagement and cancelled the wedding $1 \frac{1 / 2}{2}$ years before the start of the therapy that is the subject of this set of papers.

When Sharon began treatment, she reported receiving a variety of brief, nonsensical emails from various accounts for over a year, going back to shortly after she called off the wedding. Sharon was sure that Jeff was sending the messages (based on good evidence), although he denied being the source. Sharon had gone as far as consulting professionals who were unable to identify the sender. On the other hand, she did not change her email address for a very long time, even though her friends had counseled her repeatedly to do that.

Note that throughout that period of time, Sharon periodically contacted Jeff. One of those occasions occurred two weeks before the beginning of the therapy when Sharon called Jeff and met with him. She did that even though there had been other times when she met with Jeff and he had yelled at her publicly, blaming her for the breakup. Sharon also contacted Jeff a number of times during the course of the treatment, which became the main topic in a number of the sessions.

It was clear that Jeff had trouble controlling his temper - which, again, was Sharon's reason for wanting him to go with her to couples therapy - but Sharon played a role in making him angry. For example, in her narratives in therapy, Sharon spoke about a time early in her relationship with Jeff when he complained that she chose her friends over him. In response, Sharon insisted on spending more time with her friends. Sharon also talked about how Jeff would get annoyed when she would bring an early end to an evening that they had planned to spend together in order to get back to her apartment to see her sister, explaining that she did not want her sister to be lonely. Similarly, she talked about one occasion when she and Jeff bumped into her father when they were out for the afternoon. Sharon insisted that they go to lunch with her father, even though she saw him frequently, and Jeff got angry.

\section{Family Relationships}

Sharon described her mother as vain and self-absorbed. She also characterized her as controlling and referred to her as the "queen of the house." She said that she and her mother "get along pretty well," but that they are not open about "very personal things."

Sharon described her father as having trouble letting things go. For example, she said that he held grudges when he felt that someone had hurt him. She also reported that her father was diagnosed with "mild depression" (for which he received medication and psychotherapy for an extended period) after her sister, who is older than Sharon, left for college. As has been noted, Sharon worried about her father's health and safety, despite having little apparent need to be worried. With regard to her relationship with her father, Sharon said that they got along "very well," that "we're very close," that "I'm his little girl," and that she felt that she was closer to her father and more aligned with him than was her sister. However, she also described her father as "very overprotective" and said that although her father was actively involved with her, she felt that he would turn away from her if their involvement was not on his terms. 
Sharon reported being her father's confidante for many years about his conflicts with her mother. Sharon's father was older than her mother. Sharon described her parents' relationship as poor and said that her father was her mother's subservient "vassal."

\section{Prior Therapy Experiences and the Treatment Approach of Interest Here}

\section{Prior Therapy}

Sharon had two prior treatment attempts. Each was an attempt to deal with the same main presenting problem that also was the focus of the therapy of present concern. Sharon's second prior therapy ended just one month before the therapy of interest here began. Her first therapy attempt ended a year before that. Each of those previous treatments lasted about four months. Sharon reported that she ended those treatments because they were not helping, were too expensive, and because she felt that the therapists did not understand her. She said that both prior therapists simply encouraged her to "move on" from her relationship with her ex-fiancé.

\section{The Treatment Approach Employed in Sharon's Case}

As noted earlier, Sharon's case was part of the short-term dynamic psychotherapy condition in the umbrella investigation. The specific approach employed in that treatment condition of the larger study was Brief Adaptive Psychotherapy (BAP), which was developed by Pollack et al. (1992). This approach is similar to the short-term psychodynamically-oriented treatments developed by Luborsky (1984) and by Strupp and Binder (1984).

In BAP, therapists identify a patient's major maladaptive interpersonal pattern of beliefs and behaviors. As an example of a maladaptive pattern, Pollack et al. explained that some patients always accommodate to others, neglecting their own needs. In BAP, the goal of therapy is understood to be resolving the conflict underlying the maladaptive pattern by making unconscious material conscious and, as a result, available to the ego's capacity for adaptation. This includes helping patients achieve insights into the origin and development of the pattern and bringing a patient's unconscious fantasies into awareness to make it possible to cope more adaptively.

Therapists pursue these goals by actively keeping the focus of therapy sessions on patients' maladaptive patterns through explorations of patients' relationship experiences in childhood, in current extra-therapy relationships, and in the therapy relationship. They persistently offer interpretations and confront the patient about transference phenomena that appear in the patient's relationship with the therapist and other current relationships, directing the patient to consider how their expectations and distorted perceptions and beliefs fit in the maladaptive pattern.

In broad strokes, there are some similarities between BAP, on the one hand, and IRT and Interpersonal Defense Theory on the other. All three focus on problematic interpersonal behavior patterns and call for devoting attention to patients' relationships in childhood, their current lives, and the therapy context. These similarities provided both MW and $\mathrm{KC}$ with enough clinical material of the types needed to arrive at our own formulations of Sharon's case, as we noted 
earlier. Nevertheless, there are major differences between BAP and both of the therapy approaches of interest here.

One of the main differences is that BAP offers only a very limited account of the nature of what it refers to as maladaptive patterns, and the little that is said about those patterns - as in the example of overly accommodating patients - indicates that they are conceptualized in much simpler and certainly very different terms than how they are understood in either Interpersonal Defense Theory or IRT. In addition, BAP's accounts are more limited and quite different than what Interpersonal Defense Theory or IRT have to offer when it comes to why and how problematic interpersonal patterns develop as a result of early experiences, why those patterns continue from childhood into adulthood, and, very importantly, what maintains an adult's problematic patterns over time. Finally, BAP's ideas about therapeutic interventions, which focus on consistently confronting and interpreting appearances of maladaptive patterns, are very different than the treatment implications of both Interpersonal Defense Theory and IRT.

\section{The Therapist in Sharon's Case}

Sharon's therapist was a 39-year-old male psychiatrist. He had 9 years professional experience, including extensive prior experience with time-limited psychotherapy as a therapist and as a supervisor and one previous case as a therapist in the short-term dynamic therapy condition (i.e., BAP) of the umbrella investigation.

\section{ORIENTATION TO THE FOLLOWING PAPERS ABOUT SHARON'S CASE}

This paper sets the stage for a careful comparative consideration of Sharon's case from the vantage points of Interpersonal Defense Theory and IRT. In the first two papers that follow, $\mathrm{MW}$ in one paper and $\mathrm{KC}$ and his coauthors in the other present their respective theories in general and the theories' general implications for formulating cases and treatment; and they offer formulations of Sharon's case specifically and discuss treatment implications for her case. The two papers that follow after that have a similar structure. In the first, MW compares the two approaches to case formulation and treatment both in general terms and with regard to Sharon's case from the vantage point of Interpersonal Defense Theory. In the second, KC and his coauthors provide a parallel comparative examination from the viewpoint of IRT.

In the final two articles, Stanley Messer first offers a commentary on this project in which he first raises basic methodological/philosophy of science questions about whether it is possible to arrive at conclusions about the relative merits of our two theoretical perspectives; and he then offers interesting ideas and suggestions about that issue. This paper series ends with MW and KC together then replying to the commentary and the fundamental questions Messer raises. 


\section{REFERENCES}

Battle, C. C., Imber, S. D., Hoehn-Saric, R., Stone, A. R., Nash, E. R., \& Frank, J. D. (1966). Target complaints as criteria of improvement. American Journal of Psychotherapy, 20, 184-192.

Benjamin, L. S. (1979). Structural analysis of differentiation failure. Psychiatry: Journal for the study of interpersonal processes, 42, 1-23.

Benjamin, L. S. (1987). Use of the SASB Dimensional Model to develop treatment plans for personality disorders. I: Narcissism. Journal of Personality Disorders, 1, 43-70. https://doi.org/10.1521/pedi.1987.1.1.43

Benjamin, L. S. (1996). Interpersonal diagnosis and treatment of personality disorder. New York: Guilford Press. $2^{\text {nd }}$ ed.

Benjamin, L. S. (2006). Interpersonal reconstructive therapy: An integrative, personality-based treatment for complex case (paperback ed.). New York: Guilford Press.

Benjamin, L. S. (2018). Interpersonal reconstructive therapy for anger, anxiety, and depression: It's about broken hearts, not broken brains. Washington, DC: American Psychological Association.

Derogatis, L. R. (1983). The Symptom Checklist -90 Revised: Administration, scoring and procedures manual II. Baltimore: Clinical Psychometric Research.

Eells, T. D. (Ed.). (2007). Handbook of psychotherapy case formulation $\left(2^{\text {nd }}\right.$ ed.). New York: Guilford.

Endicott, J., Spitzer, R. L., Fleiss, J. L., \& Cohen, J. (1976). The Global Assessment Scale: A procedure for measuring overall severity of psychiatric disturbance. Archives of General Psychiatry, 33, 766-771.

Henriques, G. (2017). Character Adaptation Systems Theory: A New Big Five for personality and psychotherapy. Review of General Psychology, 21, 9-22.

Horowitz, L. M., Alden, L. E., Wiggins, J. S., \& Pincus, A. L. (2000). Inventory of Interpersonal Problems. New York: The Psychological Corporation.

Klein, M. H., Benjamin, L. S., Treece, C., Rosenfeld, R., \& Greist, J. (1993). The Wisconsin Personality Disorder Inventory: Development, reliability and validity. Journal of Personality Disorders, 7, 285-303.

Kramer, U. (Ed.). (2019). Case formulation for personality disorders: Tailoring psychotherapy to the individual patient. London: Academic Press.

Lazarus, A. A., \& Messer, S. B. (1988). Clinical choice points: Behavioral versus psychoanalytic interventions. Psychotherapy, 25, 59-70.

Luborsky, L. (1984). Principles of psychoanalytic psychotherapy: A manual for supportive expressive treatment. New York: Basic Books.

Messer, S. B. (1986). Behavioral and psychoanalytic perspectives at therapeutic choice points. American Psychologist, 41, 1261-1272.

Muran, J. C., Safran, J. D., Samstag, L. W., \& Winston, A. (2005). Evaluating an alliancefocused treatment for personality disorders. Psychotherapy, 42, 532-545.

Persons, J. B. (1991). Psychotherapy outcome studies do not accurately represent current models of psychotherapy. American Psychologist, 46, 99-106. 
Pollack, J., Flegenheimer, W., Kaufman, J., \& Sadow, J. (1992). Brief adaptive psychotherapy for personality disorders: A treatment manual. San Diego, CA: Social \& Behavioral Documents.

Spitzer, R. L., Williams, J. B. W., Gibbon, M., \& First, M. B. (1990). Structured clinical interview for DSM-III-R - patient edition (with psychotic screen) - SCID-P (w/psychotic screen) - version 1.0. Washington, DC: American Psychiatric Press.

Strupp, H. H., \& Binder, J. L. (1984). Psychotherapy in a new key: A guide to time-limited psychotherapy. New York: Basic Books.

Tracey, T. J., \& Kokotovic, A. M. (1989). Factor structure of the Working Alliance Inventory. Psychological Assessment, 1, 207-210.

Westerman, M. A. (2018). Interpersonal defense theory: An integration of philosophical considerations, psychoanalytic concepts, and perspectives on interpersonal processes that provides a guide for a wide range of therapeutic interventions. Journal of Psychotherapy Integration, 28, 310-328.

Westerman, M. A. (2019). Case formulation in interpersonal defense theory: A process model of interpersonal phenomena that play key roles in psychopathology and psychotherapy. In U. Kramer (Ed.), Case formulation for personality disorders: Tailoring psychotherapy to the individual client (pp. 315-335). London, United Kingdom: Elsevier.

Westerman, M. A., \& Muran, J. C. (2017). Investigating an approach to the alliance based on interpersonal defense theory. Psychotherapy Research, 27, 620-641. 
Pragmatic Case Studies in Psychotherapy, http://pcsp.libraries.rutgers.edu

Volume 17, Module 1, Article 2, pp. 5-18, 04-19-21 [copyright by authors]

Figure 1: Structural Analysis of Social Behavior (SASB), Full Model. Figure 2 on p. 6, Benjamin, L. S. (1979). Structural analysis of differentiation failure. Psychiatry: Journal for the Study of Interpersonal Processes, 42, 1-23. Reprinted with permission of Guilford Press.

INTERPERSONAL

120 Endorse freedom

OTHER

SELF

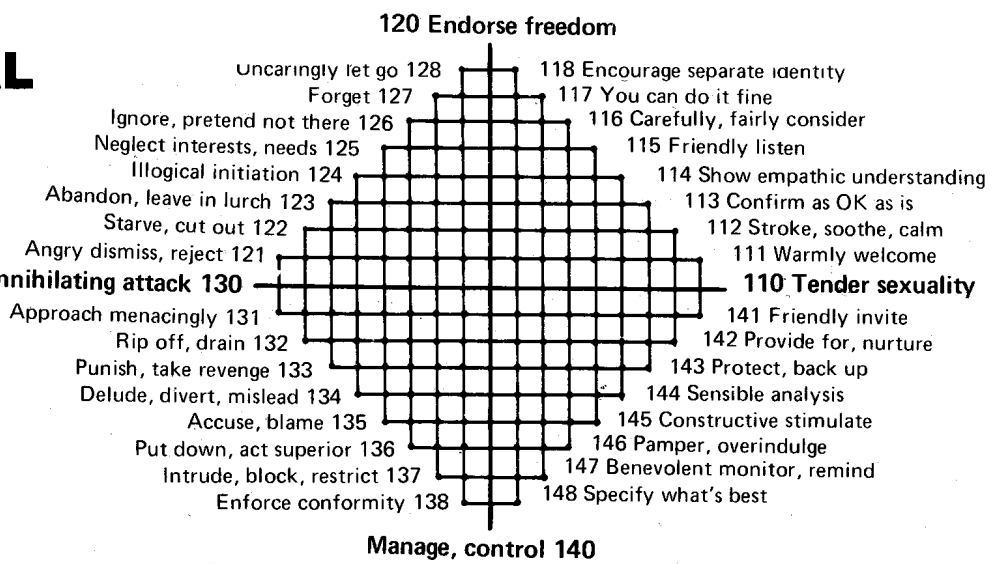

220 Freely come and go

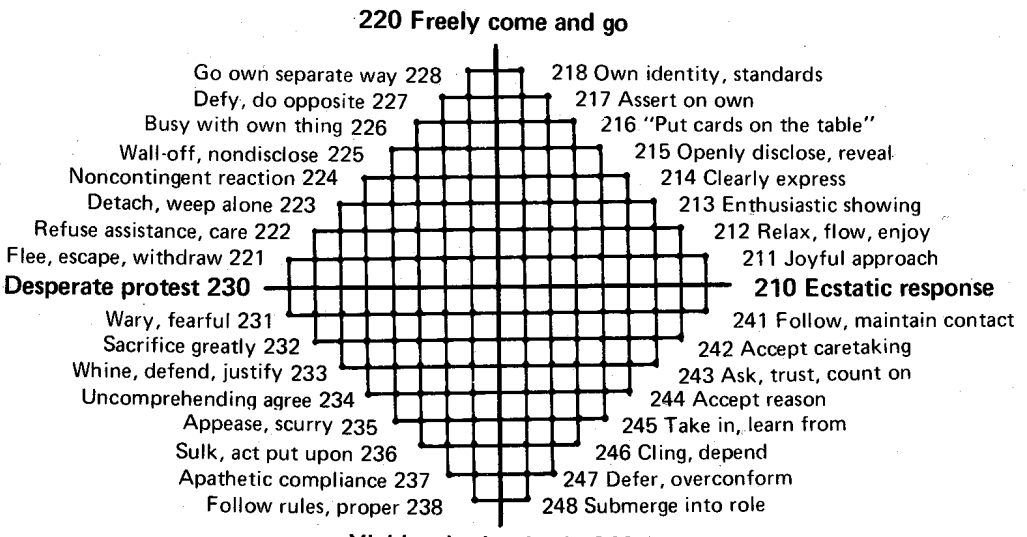

Yield, submit, give in 240

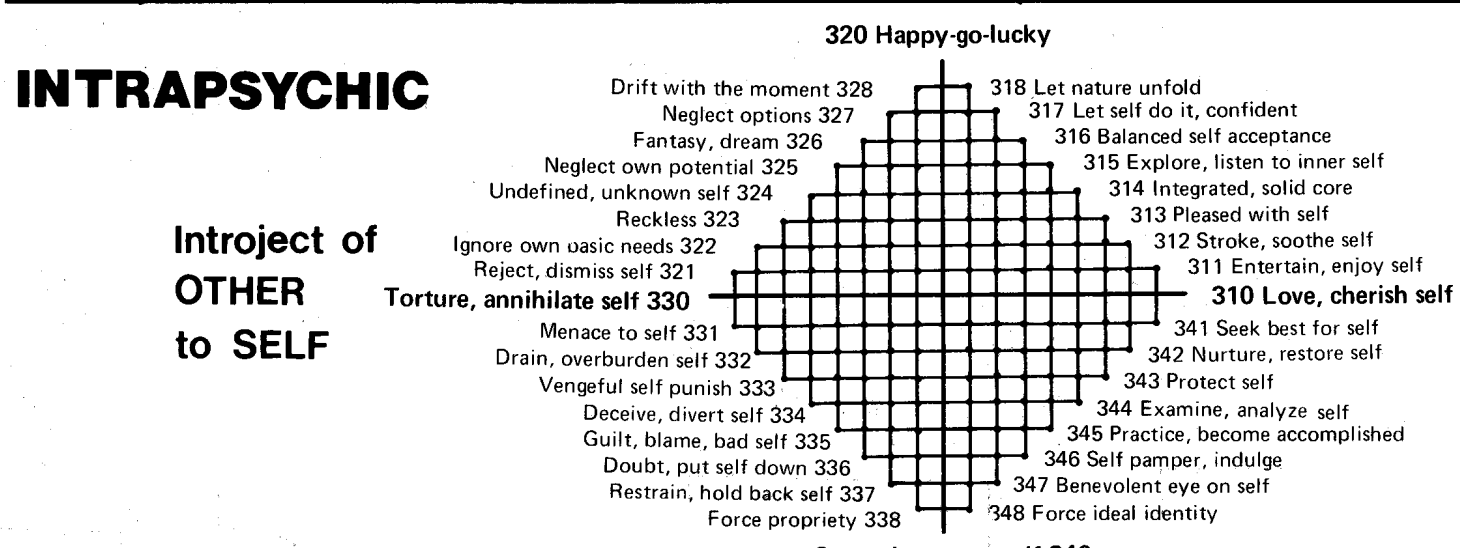

Control, manage self $\mathbf{3 4 0}$ 
Pragmatic Case Studies in Psychotherapy, http://pcsp.libraries.rutgers.edu

Volume 17, Module 1, Article 2, pp. 5-18, 04-19-21 [copyright by authors]

Figure 2: The Simplified SASB Cluster Model.

(Figure 3.9 on p. 55, Benjamin, L. S. (1996). Interpersonal Diagnosis and Treatment of Personality Disorder. NY: Guilford Press. $2^{\text {nd }}$ ed. Reprinted with permission of Guilford Press.)

\section{EMANCIPATE}

SEPARATE

SELF-EMANCIPATE

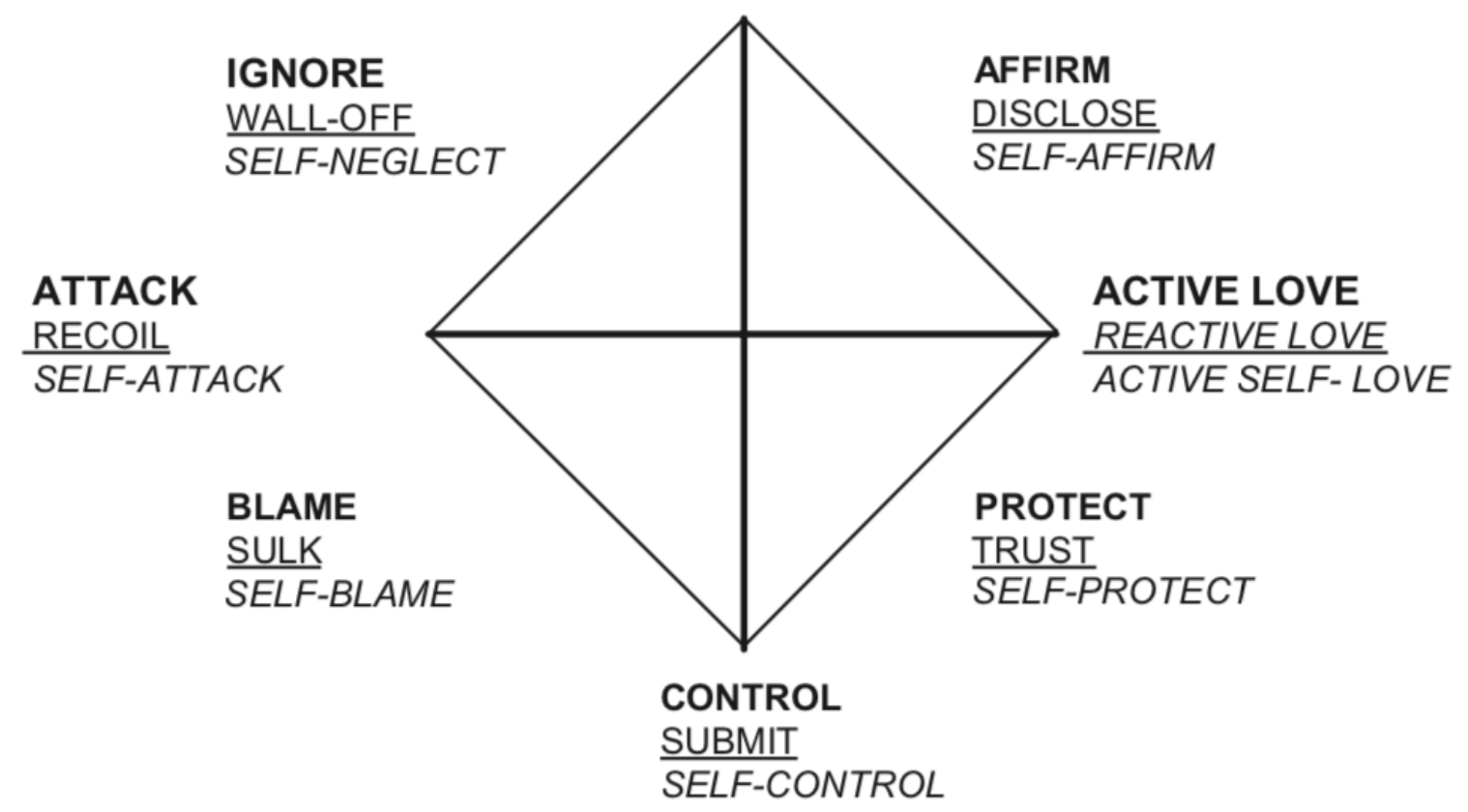

